\title{
Posterior Long Segment Instrumentation Beyond A Failed Percutaneous Vertebroplasty
}

\author{
Abdusattarov Khurshid*, Khujanazarov Ilkhom, Alimov Ijod and Alihodjaeva Gulnara \\ Department of Traumatology, Orthopedics, Military field Surgery and Neurosurgery, Tashkent Medical Academy, Uzbekistan
}

Submission: February 20, 2020; Published: March 02, 2020

*Corresponding author: Abdusattarov Khurshid, Department of Traumatology, Orthopedics, Military field Surgery and Neurosurgery, Tashkent Medical Academy, Tashkent, Uzbekistan

\begin{abstract}
There are several controversial challenges in the treatment of compression vertebral fractures in patients with osteoporosis, one of the main issues of treatment is the optimal surgical approach selection with the minimal risk of complications. Percutaneous vertebral augmentation modalities such as Percutaneous Vertebroplasty (PVP) and Percutaneous Kyphoplasty (PKP) are minimally invasive surgical procedures for treating painful compression vertebral fractures in patients with osteoporosis. Specific complications of vertebral augmentation modalities (PVP/PKP) are associated with the high risk of bone cement leakage. Prevention and management of complications related to the PVP/PKP are important challenges for the spine surgeons to date. The assessment of risk factors such as Intervertebral Cleft (IVC), cortical disruption, cement viscosity, and injected cement volume can prevent the complications related to the PVP/PKP. To optimize the benefits of PVP/PKP the risk analysis of each complication should be made, and appropriate treatment strategies of complications related to PVP/PKP should be established.

Keywords: Percutaneous vertebroplasty; Percutaneous kyphoplasty; Bone cement leakage
\end{abstract}

\section{Introduction}

The International Society for the Advancement of Spine Surgery (ISASS) advocates that Percutaneous Vertebroplasty (PVP) and Percutaneous Kyphoplasty (PKP) are effective minimally invasive treatment modalities for patients with painful Vertebral Compression Fractures (VCFs) [1]. The principal goal of PVP /PKP is to fill the fracture cleft with cement to provide vertebral body mechanical stability; the second goal of performing PVP/PKP is to improve the sagittal alignment and biomechanics of the functional spinal unit; both of those effects provide significant pain relieve and improve the quality of the life of patients after surgery [2]. Despite significant advantages of PVP /PKP in the treatment of VCFs, the Cement Leakage (CL) is one of the major complications for both procedures, which may lead to adverse clinical sequelae $[3,4]$. The recent retrospective study reported the relatively high incidence of cement extravasation $43 \%$ and $30 \%$, respectively for PVP and KPV; of them into prevertebral soft tissues in (41\% / 45\%), into paravertebral veins (26\% / $23 \%)$, into intradiscal space $(33 \%$ $/ 27 \%)$, and into spinal cord (1.2\% / 6\%), accordingly for PVP and PKP [5]. Up to now, the best surgical management of subsequent complications of PVP/PKP is still a matter of discussion; currently there are no evidence-based treatment guidelines for the proper surgical approach and the instrumentation technique.

The prevention and treatment of complications related to PVP/PKP are one of major concern in spine surgery; to optimize the benefits of PVP/PKP the risk analysis of each complication should be made. [5]. The recent comprehensive meta-analysis has demonstrated that Intervertebral Cleft (IVC), cortical disruption, cement viscosity, and injected cement volume can be the significant risk factors for the cement leakage. This study revealed that in comparison the IVC group patient's with the no IVC group patients, the risk of cement leakage after PVP or PKP was significant higher in IVC group (OR, 1.40; $\mathrm{P}<0.01$ ) Furthermore, when it was compared group of patients with no cortical disruption and cortical disruption, the results demonstrated that the risk of cement leakage was 5 -fold higher after PVP / PKP (OR, 5.56; P < 0.01) in cortical disruption group then in the group of patients without cortical disruption. The comparison of high, medium, low viscosity cements revealed that the low-viscosity cement had a more than 3-fold higher risk of cement leakage after PVP / PKP (OR, 3.32; P < 0.01). The analysis of the injected cement volume revealed that there was a 
statistically significant and positive correlation between injected cement volume and cement leakage after PVP /PKP (WMD, 0.59; P $<0.05$ ) [6]. Identification and assessment of risk factors affecting to the cement leakage are critically important for appropriate patient's selection to the PVP/PKP.

Another potential challenge is to define the optimal treatment algorithm in case of a cement encroachment into the spinal canal, which can lead to the spinal canal compression post PVP/ PKP. Currently, the operative treatment modalities succeeding failed PVP /KPP can be ranged from minimally invasive reaugmentation of the collapsed vertebra to the open or minimal invasive anterior/posterior instrumentations of the spine, or a combination of those surgical procedures. In the present case (Figure 1), the PVP was performed for the treatment compression vertebral fractures of the body Th12, however 3 weeks after the initial surgery, it was noted that bone cement encroachment into the spinal canal. The second surgery was open long-segment posterior fixation LSPF (2 levels above and 2 levels below of the fractured vertebra); this surgical modality provides enough stabilization without incurring the risks of posttraumatic kyphosis, implant breakage, and late neurologic deficit (Figure 2). The determination of the level of instrumentation of the spinal fractures is widely discussed in the literature to date, there are many studies compared the biomechanical and clinical outcomes of SSPF /LSPF constructs without fixation of the fracture level [7]. The results showed that SSPF/LSPF have the same radiographic outcomes (local kyphosis, sagittal index, anterior body height compression) [8]. The difference between SSPF and LSPF is that SSPF significantly declines the surgical time and preserves more vertebral motion segments, however the implant failure is less in the LSPF fixation than that of SSPF fixation [9]. It should be stressed that four-segment pedicle fixation is the most suitable option for osteoporotic patients, according to fundamental biomechanical principles, this structural uniform provides the greatest mechanical stiffness for initial fixation and can reduce the likelihood of segmental collapse [10].

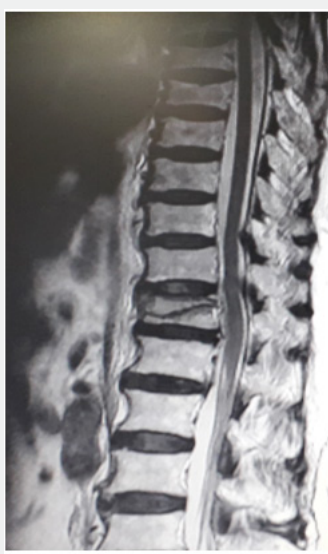

a)

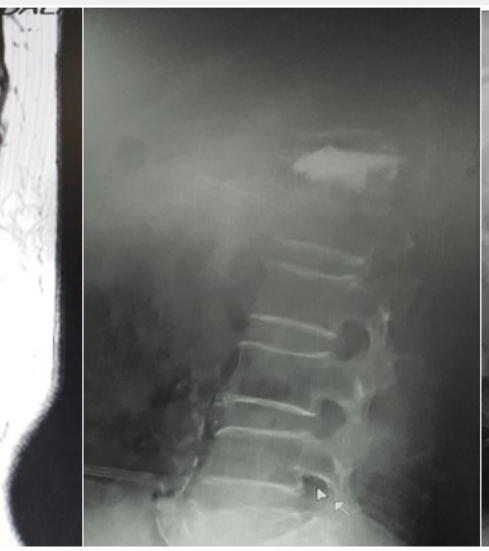

b)

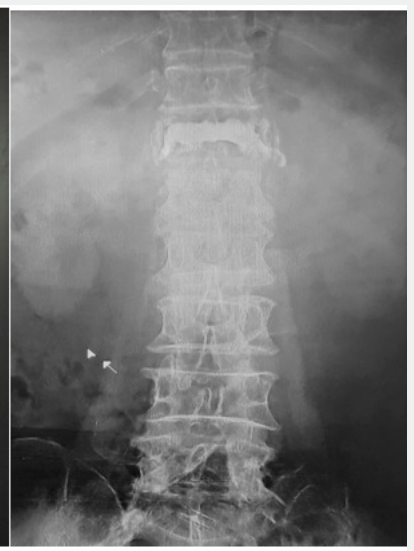

c)

Figure 1: The patient K. was 69 years old women. Pre-operative MRI (a) sagittal view of the compression fracture of the Th12 vertebral body; post-operative lateral (b) and frontal (c) X-ray images, percutaneous vertebroplasty (PVP) of the compression fracture of Th12 vertebral body with polymethyl methacrylate (PMMA).

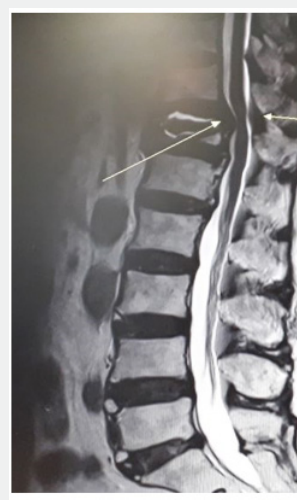

a)

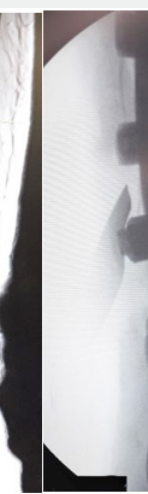

b)

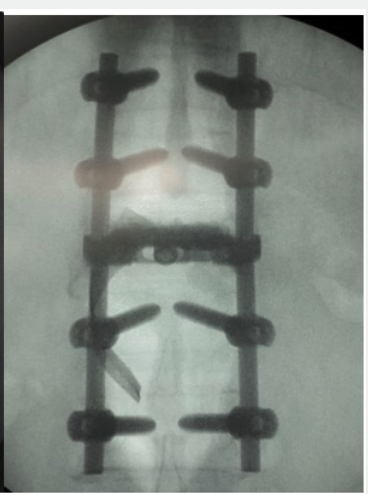

c)

Figure 2:The patient K. was 69 years old women. the radiological evaluation 3 weeks after PVP.

Pre-operative MRI (a) sagittal view, cement encroachment into the spinal canal after PVP of Th12; postoperative lateral (a) and frontal (c) X-ray images, internal posterior long segment stabilization Th10/11-L1/L2. 
In conclusion, the percutaneous vertebral augmentation techniques such as PVP or KVP are safe and effective treatment modality for the patients with OVCFs; the radiological and clinical outcomes are good in more than $90 \%$ of cases and complications occur in less than $1 \%$ of interventions [11]. Comprehensive preoperative assessment of risk factors for bone cement leakage leakage can prevent intra- and postoperative complications related to the PVP /PKV procedures [12].

\section{References}

1. Clerk-Lamalice O, Beall DP, Ong K, Lorio MP (2019) ISASS Policy 2018-Vertebral Augmentation: Coverage Indications, Limitations, and/ or Medical Necessity. Int J Spine Surg 13(1): 1-10.

2. Zhang Y, Liu H, He F, Chen A, Yang H, et al. (2020) Safety and efficacy of percutaneous kyphoplasty assisted with 0 -arm navigation for the treatment of osteoporotic vertebral compression fractures at T6 to T9 vertebrae. Int Orthop 44(2): 349-355.

3. Ebeling PR, Akesson K, Bauer DC, Buchbinder R, Eastell R, et al. (2019) The Efficacy and Safety of Vertebral Augmentation: A Second ASBMR Task Force Report. J Bone Miner Res 34(1): 3-21.

4. Alimov I, Abdusattarov K (2018) Percutaneous Vertebroplasty as a Treatment for Osteoporotic Vertebral Compression Fractures. J Head Neck Spine Surg 2(5): 555597.

5. Semaan H, Obri T, Bazerbashi M, Paull D, Liu X, et al. (2018) Clinical outcome and subsequent sequelae of cement extravasation after percutaneous kyphoplasty and vertebroplasty: a comparative review. Acta Radiol 59(7): 861-868.

6. Zhan Y, Jiang J, Liao H, Tan H, Yang K (2017) Risk Factors for Cement Leakage After Vertebroplasty or Kyphoplasty: A Meta-Analysis of Published Evidence. World Neurosurg 101: 633-642.

7. Joaquim AF, Maslak JP, Patel AA (2019) Spinal Reconstruction Techniques for Traumatic Spinal Injuries: A Systematic Review of Biomechanical Studies. Global Spine J 9(3): 338-347.

8. Blattert TR, Schnake KJ, Gonschorek O, Katscher S, Ullrich BW, et al. (2019) [Nonsurgical and surgical management of osteoporotic vertebral body fractures: Recommendations of the Spine Section of the German Society for Orthopaedics and Trauma (DGOU)]. Orthopade 48(1): 84-91.

9. Aono H, Ishii K, Takenaka S, Tobimatsu H, Nagamoto Y, et al. (219) Risk factors for a kyphosis recurrence after short-segment temporary posterior fixation for thoracolumbar burst fractures. J Clin Neurosci 66: 138-143.

10. Wu Y, Chen CH, Tsuang FY, Lin YC, Chiang CJ, et al. (2019) The stability of long segment and short-segment fixation for treating severe burst fractures at the thoracolumbar junction in osteoporotic bone: A finite element analysis. PLoS One.

11. Langner S, Henker C (2020) Vertebroplasty and kyphoplasty: A critical statement. Radiologe 60(2): 138-143.

12. Alimov I, Khujanazarov I, Abdusattarov K (2018) Modern Treatment Approaches for Osteoporotic Low-Traumatic Vertebral Body Fractures. Biomed J Sci \& Tech Res 7(1).

\section{Your next submission with Juniper Publishers will reach you the below assets}

- Quality Editorial service

- Swift Peer Review

- Reprints availability

- E-prints Service

- Manuscript Podcast for convenient understanding

- Global attainment for your research

- Manuscript accessibility in different formats

( Pdf, E-pub, Full Text, Audio)

- Unceasing customer service

Track the below URL for one-step submission https://juniperpublishers.com/online-submission.php 